\title{
INFLUENCE OF BORIDATION ON MICROSTRUCTURE AND Properties Of Aluminium Alloy EN AW-2024
}

\author{
David Bricín, Zbyněk Špirit \& Antonín Křriž
}
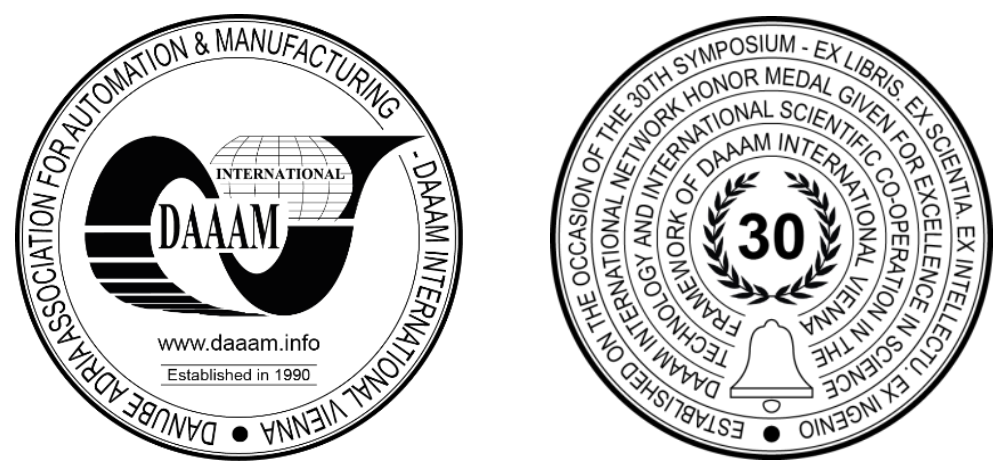

This Publication has to be referred as: Bricin, D[avid]; Spirit, Z[bynek] \& Kriz, A[ntonin] (2020). Influence of Boridation on Microstructure and Properties of Aluminium Alloy EN AW-2024, Proceedings of the 31st DAAAM International Symposium, pp.0477-0484, B. Katalinic (Ed.), Published by DAAAM International, ISBN 978-3-90273429-7, ISSN 1726-9679, Vienna, Austria

DOI: $10.2507 / 31$ st.daaam.proceedings.067

\begin{abstract}
The aim of this case study was to analyse the influence of the boriding process on the structure and mechanical properties of the aluminium alloy EN AW 2024. The prepared samples were processed under various process parameters in Durferrit powder. After chemical-thermal treatment, changes in the microstructure of the samples were evaluated using light and scanning electron microscopy methods. Changes in mechanical properties were assessed on the basis of the analysis of the hardness of the sample substrate using the Vickers hardness test. The samples were further measured for corrosion resistance to the selected corrosion environment of $5 \% \mathrm{NaCl}$ solution using a potentiostat and resistance to tribological abrasion by the Ball on-disk method. Based on the obtained data, it can be stated, for example, that during the boriding process of this alloy it is important to prevent the formation of a passivation layer of $\mathrm{A} 12 \mathrm{O} 3$ before and during the process of chemical-thermal treatment. This can be achieved, for example, by immediate application of a boriding agent or other agent which prevents the interaction of oxygen with the surface of the sample to be treated. The samples after the boriding process also showed an increase in the resistance to the used corrosive environment of $5 \% \mathrm{NaCl}$ solution and a lower value of the wear coefficient compared to the samples without chemical-thermal treatment.
\end{abstract}

Keywords: boriding; EN AW 2024; wear resistance; precipitates; corrosion resistance

\section{Introduction}

Aluminium alloy EN AW 2024 is one of the so-called hardenable aluminium alloys, which are used in various applications including the aviation and automotive industries. Its wide range of uses is due to the fact that it is alloy with low specific gravity, good machinability and high strength, which can be further changed using a suitably selected method of heat treatment. [1], [2], [3].

One of the most commonly used heat treatment methods for this and other aluminium alloys is curing. The curing process consists of solution annealing, quenching and subsequent aging of the Al alloy. During the solution annealing, which takes place in this alloy at temperatures around $500{ }^{\circ} \mathrm{C}$, the additive elements (precipitates) dissolve in the $\mathrm{Al}$ matrix to form a solid solution. Solution annealing is usually followed by rapid cooling of the alloy, for example by immersion in water, which suppresses diffusion phenomena. It is leads to saturation of the high-temperature structural phase (solid solution) at room temperature and thus forms a so-called supersaturated solid solution. 
From this supersaturated solution, precipitates are formed again, either at room temperature, i.e. during the natural aging of the $\mathrm{Al}$ alloy, or at elevated temperatures, when it is called artificial aging [4]. The method of precipitation, the shape, size, chemical and phase composition of the precipitates and the grain size of the matrix then to a large extent influence the properties of the aluminium alloy after its hardening process. The final structure of the $\mathrm{Al}$ alloy is thus largely dependent on the parameters of the individual processes used for processing it. There is currently a large body of scientific work that describes the effects of curing on the microstructure and the mechanical properties of this and other aluminium alloys [1], [2], [3], [4], [5], [6], [7], [8], [9], [10].

In most of the articles mentioned above, solution annealing is performed with the aid of molten metal salts or in furnaces with an inert atmosphere of argon or vacuum. In this study, we focused on assessing the effect of boriding on the final properties of aluminium alloy EN AW 2024. Boron as an element, together with aluminium, forms several types of solid solutions and intermediate phases. [11], [12], see Fig. 1.

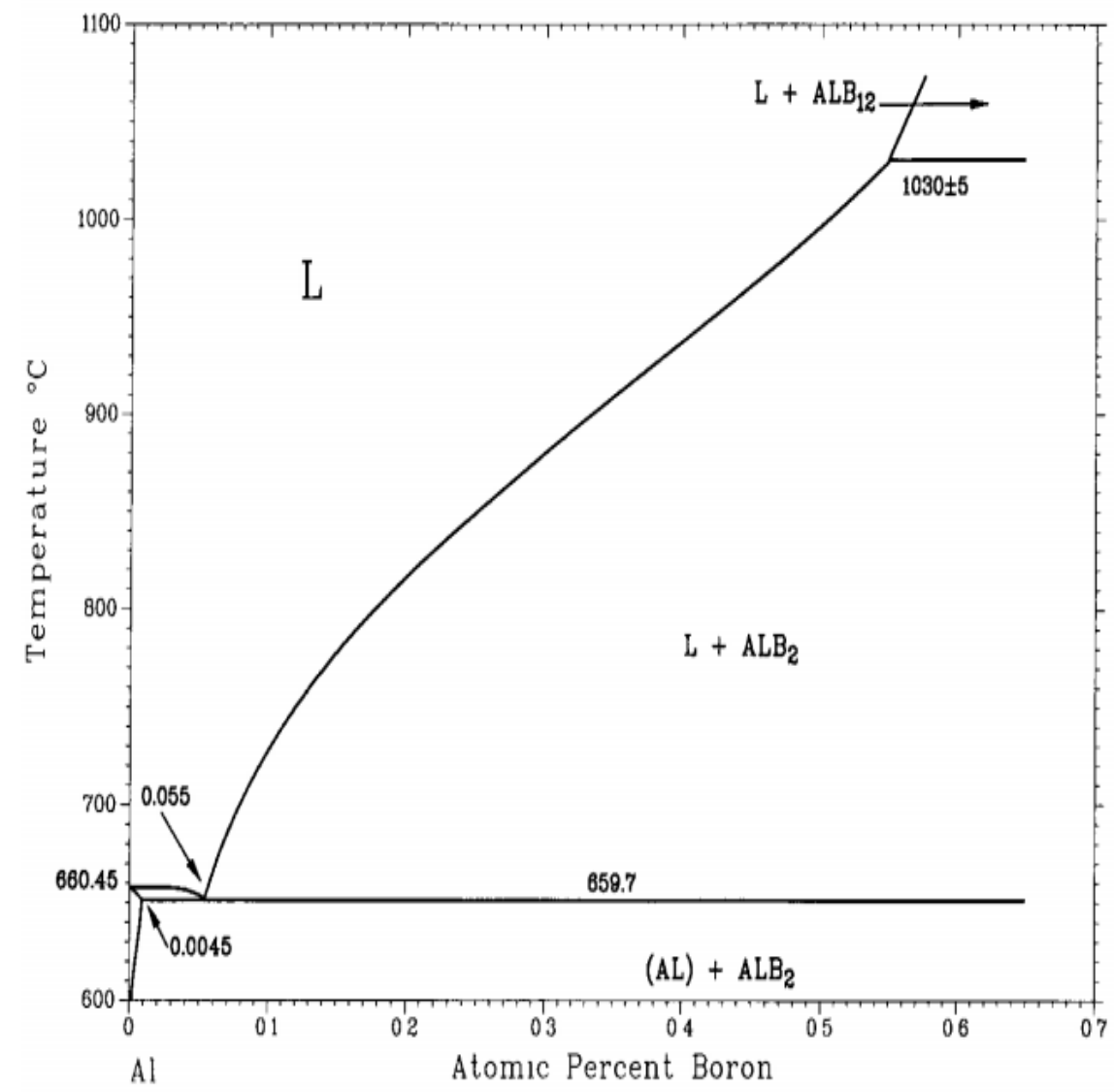

Fig. 1. Phase Diagram Al-B[12]

Aluminium borides are then used in various applications. Those common uses include the use of Al-B master alloys to produce electrically conductive aluminium. Here, boron reacts with impurities of transition metals $(\mathrm{Cr}, \mathrm{Ti}, \mathrm{V}, \mathrm{Zr})$, which reduce its electrical conductivity. During the reaction of boron with these metals, various types of borides of transition metals are formed, which no longer significantly affect its electrical conductivity and can be removed from aluminium by gravity deposition [13], [14]. Another application is their use for the production of particulate composite materials with a metal matrix (MMC) [15], [16]. These MMCs then have a high resistance to creep, abrasion resistance and, for example, electrical conductivity, making them applicable, for example, to railway vehicles or automobiles, where they are used as brake discs or pistons [16], [17], and [18].

The aim of this study was to assess whether the conventional method of boriding the alloy EN AW 2024 in the boron powder leads to significant changes in its properties, i.e. in its hardness, abrasion resistance, corrosion resistance and microstructure, due to the exclusion of borides in its structure or due to the influence of the morphology of the precipitates and surface layers formed by boron and other elements which are part of the boriding powder.

\section{Experiment parameters}

Samples with a diameter of $25 \mathrm{~mm}$ and a height of $15 \mathrm{~mm}$ were prepared from aluminium alloy EN AW 2024. The surfaces of the samples were ground and polished before treatment using Tegramin 20 metallographic grinder. The parameters of the heat treatment are shown in Table. 1." 


\begin{tabular}{|c|c|c|c|c|}
\hline \multirow{2}{*}{$\begin{array}{l}\text { Samples } \\
\text { series }\end{array}$} & \multirow{2}{*}{ Heat treatment } & \multicolumn{3}{|c|}{ Heat treatment parameters } \\
\hline & & Temperature & Holding time & Cooling \\
\hline 1 & $\begin{array}{c}\text { Original state } \\
\text { without heat } \\
\text { treatment }\end{array}$ & 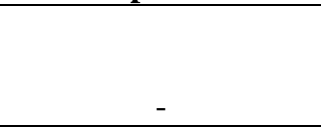 & 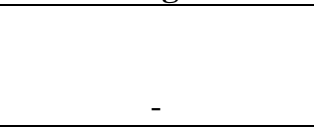 & 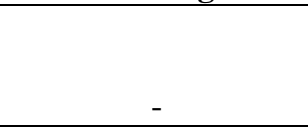 \\
\hline 2 & T6 & 190 & 720 & Air \\
\hline 3 & $\mathrm{~T} 4$ & 25 & 7200 & Air \\
\hline 4 & Boriding V1 & 500 & 240 & Box \\
\hline 5 & Boriding V1+ T6 & see parameters above & see parameters above & see parameters above \\
\hline 6 & Boriding V1+ T4 & see parameters above & see parameters above & see parameters above \\
\hline 7 & Boriding V2 & 500 & 3600 & Box \\
\hline 8 & BoridingV2+ T6 & see parameters above & see parameters above & see parameters above \\
\hline 9 & Boriding V2+ T4 & see parameters above & see parameters above & see parameters above \\
\hline 10 & Annealing V1 & 500 & 240 & Furnace \\
\hline 11 & Annealing V1+T6 & see parameters above & see parameters above & see parameters above \\
\hline 12 & Annealing V1+T4 & see parameters above & see parameters above & see parameters above \\
\hline 13 & Annealing V2 & 500 & 3600 & Furnace \\
\hline 14 & Annealing V2+T6 & see parameters above & see parameters above & see parameters above \\
\hline 15 & Annealing V2+T4 & see parameters above & see parameters above & see parameters above \\
\hline
\end{tabular}

Table 1. Parameters used to process the samples

Metallographic analysis of samples after heat treatment was performed to determine the changes caused by the heat treatment process in terms of the chemical composition of the alloy and changes in the morphology of precipitates before and after the treatment. This analysis was performed using a CarlZeiss Observer Z1m light microscope, and electron microscopy using PHILIPS XL30 ESEM and Tescan MIRA3 microscopes. Metallographic analysis was supplemented by analysis of the hardness of the sample matrix. The measurement was performed with a Vickers median HV0.1 using a DuraScan hardness tester. The surfaces of the samples were analyzed for resistance to tribological abrasion by the Ball on Disk method. In this test, a ball made of $6 \mathrm{~mm}$ diameter tungsten carbide was pressed into the rotating surface of the sample with a force of $10 \mathrm{~N}$. The number of repetitions for this test was set to a thousand cycles. The tribological footprint was evaluated using the ASTM G99 standard, according to which the volume of material removed and the wear coefficient W were calculated, see equations 1 and 2. [19].

$$
\begin{aligned}
& V=\frac{\pi(\text { wear track radius, } \mathrm{mm})\left(\text { track width }, \mathrm{mm}^{3}\right)}{6(\text { sphere radius }, \mathrm{mm})}\left[\mathrm{mm}^{3}\right] \\
& W=\frac{V}{L \cdot s}\left[\frac{\mathrm{mm}^{3}}{N \cdot m}\right]
\end{aligned}
$$

Where:

V... Worn volume (removal of material) [mm3]

L... Normal load (Fn) [N]

$\mathrm{s} .$. The total length of the path of movement of the indenter [m]

The last analysis was the change in the corrosion resistance of the processed alloy. This analysis was performed in $5 \%$ aqueous $\mathrm{NaCl}$ solution. A BioLogic SP-150 potentiostat was used for sample analysis.

\section{Experiment results}

\subsection{Metallographic analysis}

Two types of precipitates were identified in the structure of the aluminium alloy before the heat treatment, see Fig. 2. The first were precipitates of the $\mathrm{Al}-\mathrm{Cu}-\mathrm{Mg}$ type (the dark particles in Figure 2). The second type of precipitates identified were $\mathrm{Al}-\mathrm{Mn}-\mathrm{Fe}-\mathrm{Cu}$ precipitates (the light particles, see Fig. 2). It can be seen from the image that the first type of precipitates is finer and occurs more often in the structure of this alloy than precipitates of the Al-Mn-Fe-Cu type. 
The coarser particles of Al-Cu-Mg precipitates then accumulate in certain areas of the material volume, in the socalled 'lined' areas, which were formed during the forming of the semi-finished product of this alloy. The Al-Mn-Fe-Cu type additives then occurred in this alloy due to its contamination by iron during the production of the semi-finished product. The distribution of both types of precipitates, their roughness and their volume representation then to a large extent affect the mechanical properties of the alloy, i.e. its hardness, abrasion resistance and, for example, fracture toughness.

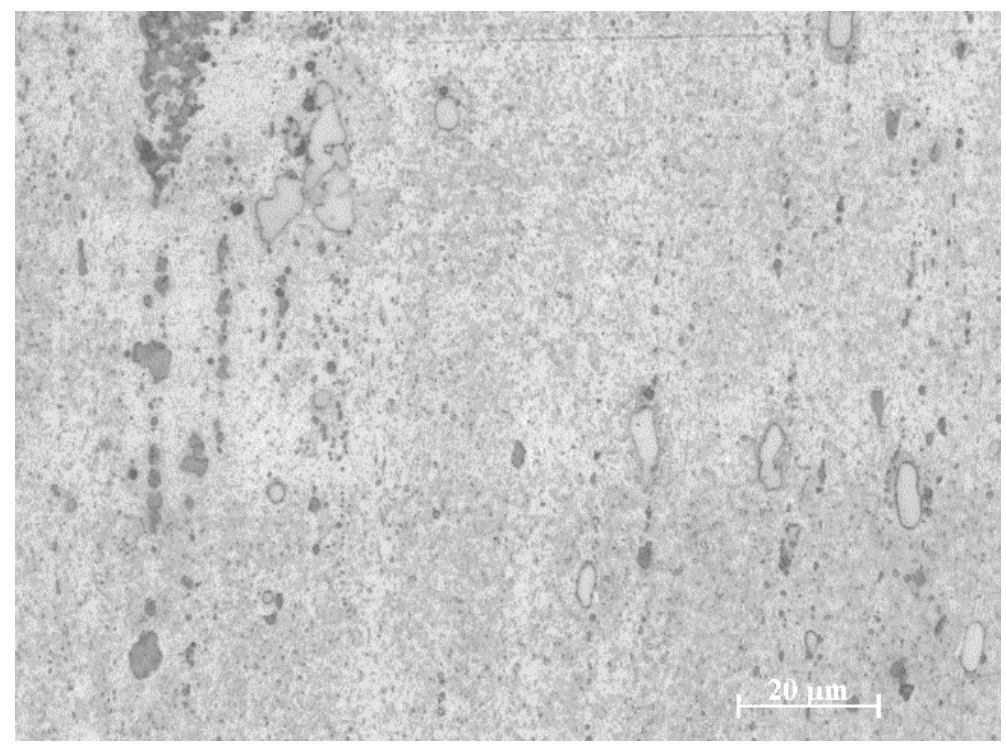

Fig. 2. EN AW 2024, without heat treatment

During the heat treatment process, the precipitates gradually dissolved into the aluminium alloy matrix. Because the elements dissolved into a solid solution, the hardness of the alloy decreased after its heat treatment, see Fig. 5. A comparison of the microstructure in the image, see Fig. 3 and 4, shows a difference in the precipitation of precipitates in the structure of the samples after the boriding process and after the long-term annealing process.

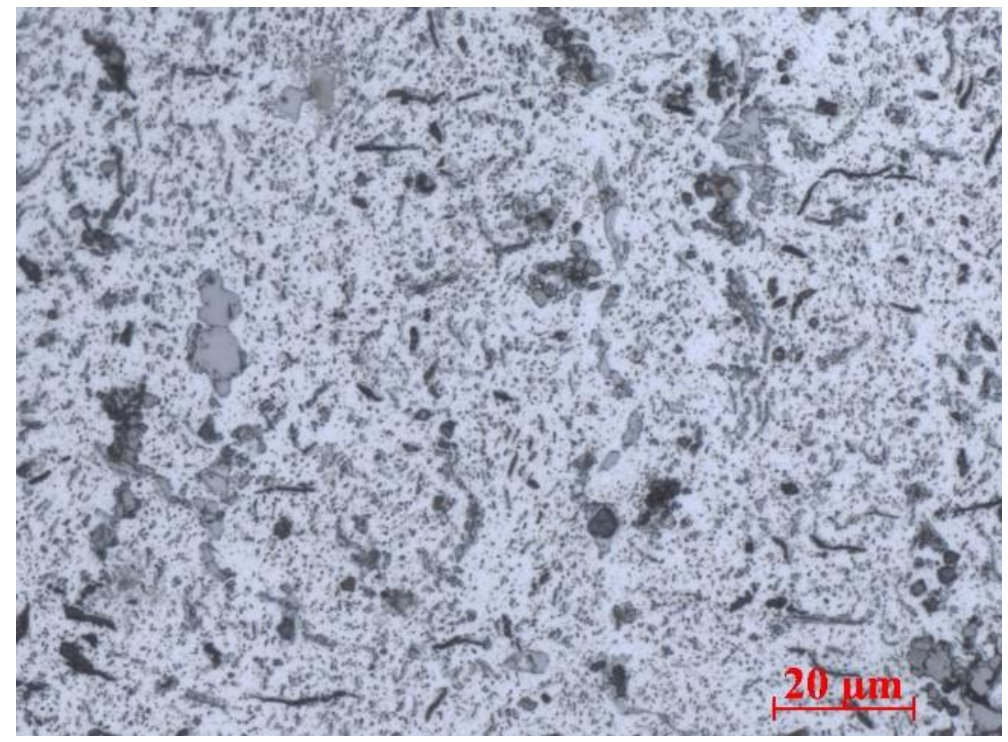

Fig. 3. EN AW 2024, borided V2

When comparing the distribution of precipitates in the structure of the samples with the original microstructure, it is further apparent that the precipitates are more evenly distributed in the matrix of the EN AW 2024 alloy due to both heat treatment methods. It can be seen from figures 3 and 4 that the structure of the matrix after boriding is formed by a higher proportion of small precipitates of the $\mathrm{Al}-\mathrm{Cu}-\mathrm{Mg}$ type, compared to the samples which were annealed for a long period of time. This may be due to the fact that during the process of their dissolution into the alloy matrix, they stabilized due to their interaction with boron, as boron binds to the free interstitial positions in the crystal lattice of the precipitate and thus increases the stress at its boundary. 
This increases the energy required for further diffusion of the substitution elements and thus reduces the rate of their diffusion and re-precipitation to coarser precipitates, resulting in more stable precipitates. The method of precipitation could be further influenced by a slightly different rate of cooling of the long-term annealed samples in the furnace, which is slower than in the borided samples, and thus the diffusion of the elements could take place over a longer period of time. However, this would result in re-coarsening of the $\mathrm{Al}-\mathrm{Cu}-\mathrm{Mg}$ precipitates, which was not observed.

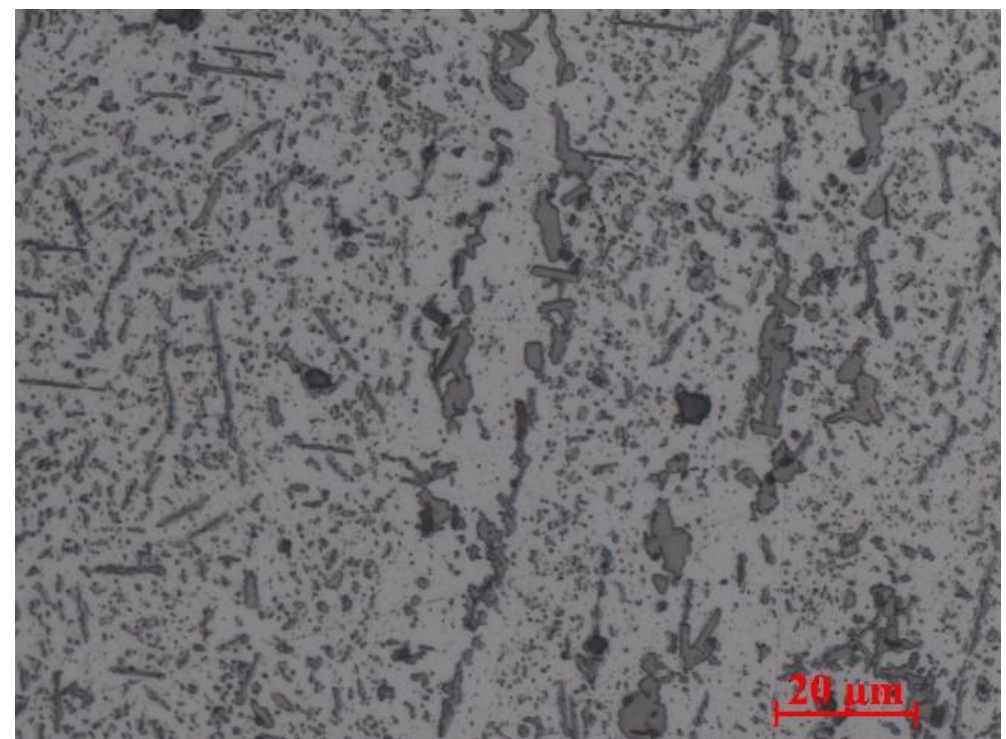

Fig. 4. EN AW 2024, annealed V2

For Al-Mn-Fe-Cu type precipitates, the change in their morphology was not so significant and corresponded to their state before heat treatment. This is associated with their chemical composition, where the presence of iron increases their thermal stability. Despite the recorded differences in the microstructure of the samples, the measurement of the hardness HV0.1 did not show a fundamental difference in the hardness of the matrix of the samples after their heat treatment by long-term annealing and boriding. Significant differences were recorded for samples that were further cured, where the largest difference was recorded for samples that were aged naturally, i.e. at room temperature of $20^{\circ} \mathrm{C}$, see Fig. 5 .

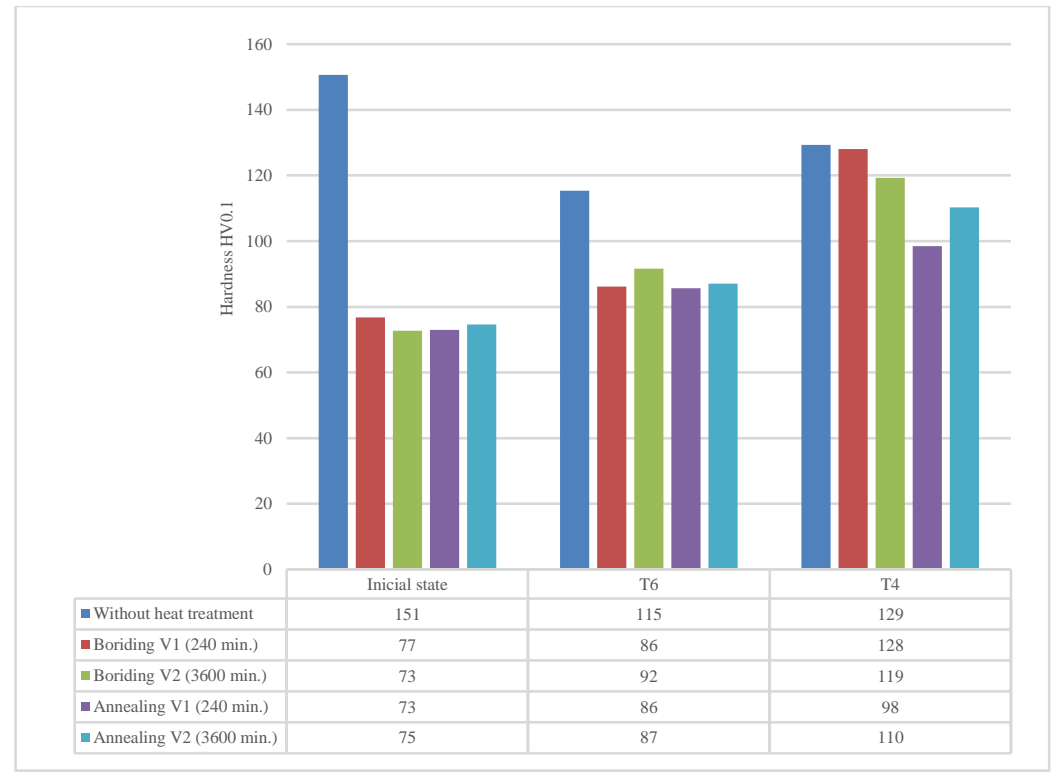

Fig. 5. Comparison of micro hardness of HV0.1 matrix of samples after their heat treatment

Samples in this state showed higher hardness than long-term annealed samples by about $23 \%$ for samples processed for 240 minutes and about $8 \%$ for samples processed for 3600 minutes. For samples aged artificially at an elevated temperature of $190{ }^{\circ} \mathrm{C}$, the hardness of the samples was similar, with the highest hardness shown in samples that were borided for 3600 minutes. In addition to the changes recorded in the matrix of the aluminum alloy EN AW 2024, a continuous layer formed on its surface, see Fig. 6. 


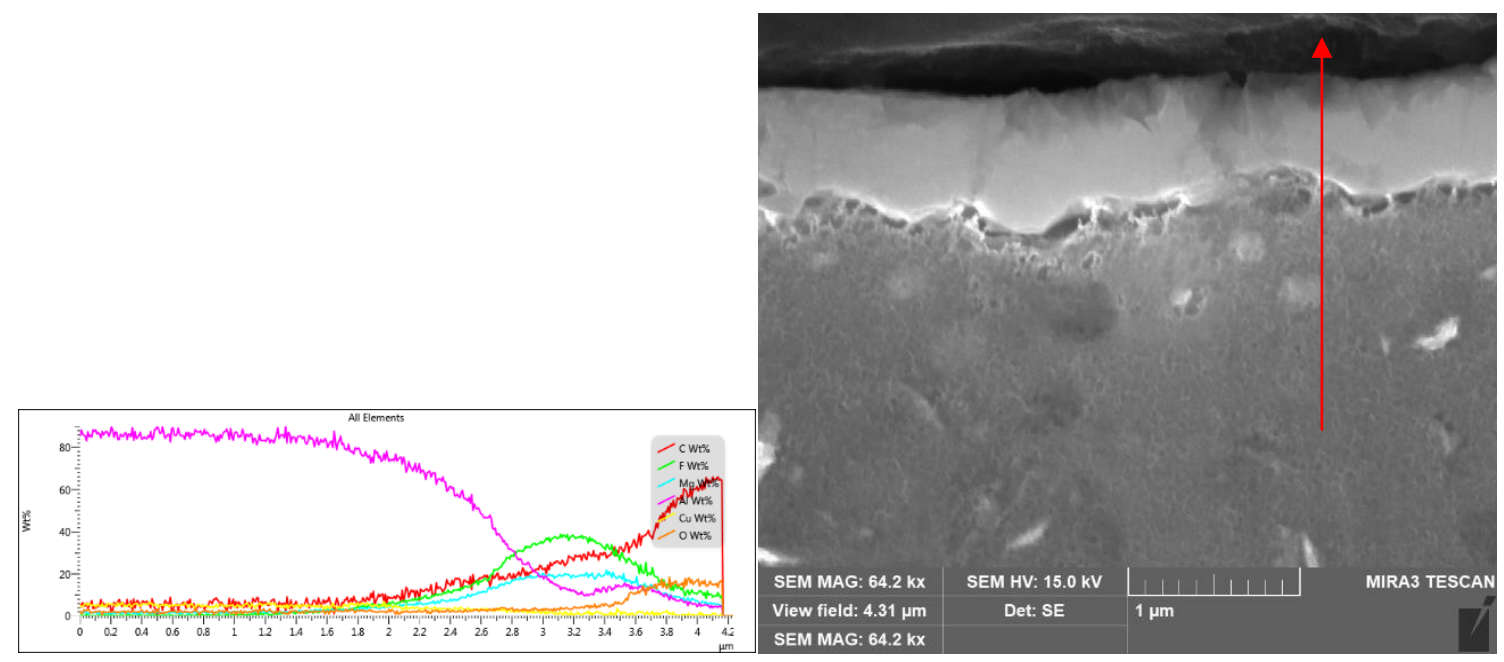

Fig. 6. The chemical composition of the surface layer boriding V1

This layer was formed by a higher proportion of magnesium, which diffused from the volume of material under the layer and fluoride, from the boriding agent, see Fig. 6 . The presence of boron could not be detected in this layer by the chemical composition method used, the EDX method. The thickness of this layer was in the order of microns. During boriding for 3600 minutes its thickness reached a maximum value of about $2 \mu \mathrm{m}$. In addition to the formation of this layer, the presence of a passivation layer of $\mathrm{Al} 2 \mathrm{O} 3$ was recorded in some samples. The formation of this layer was reduced by immediately immersing the samples after surface preparation in alcohol or boriding agent. The second method tested, which also helped to reduce its occurrence on the surface of the samples, was to dust the sample surface with calcium chloride. The reason for its removal was the fact that the presence of the $\mathrm{A} 12 \mathrm{O} 3$ layer on the surface of the samples prevents the diffusion of boron into the volume of the material and thus prevents its interaction with the matrix of the treated alloy.

\subsection{Tribology and corrosion resistance}

The formation of passivation layers and changes in the morphology of the precipitates then affected the tribological properties of the surface of the heat-treated samples, see Fig. 7.

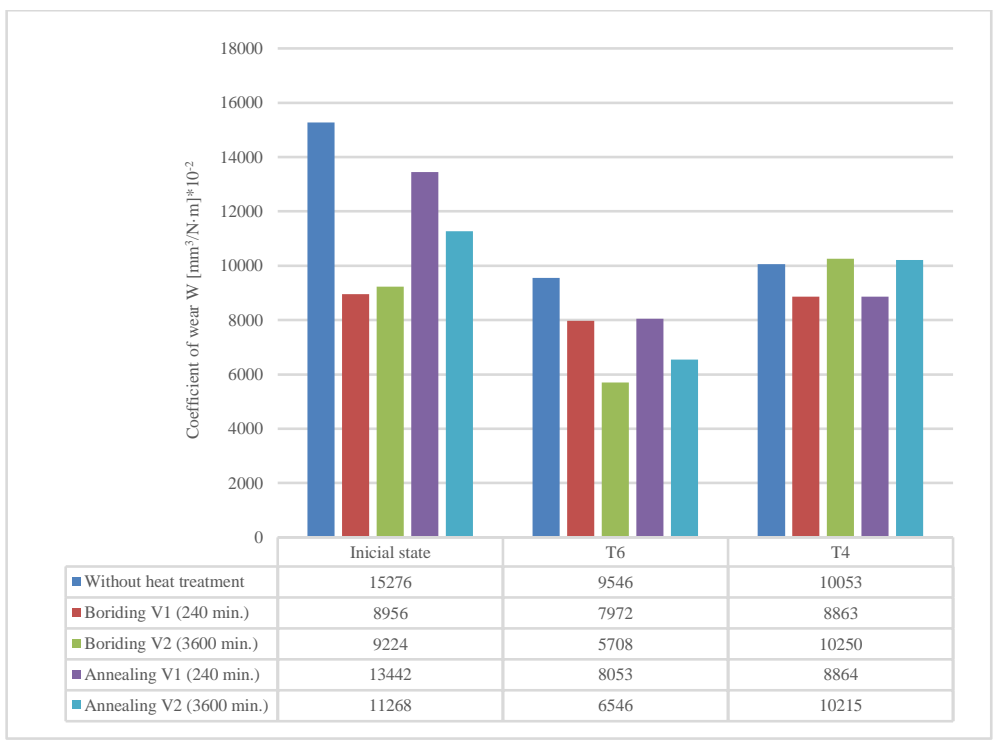

Fig. 7. Comparison of the wear coefficient of samples after their heat treatment

Abrasion resistance is further dependent on the proportion of alloying elements dissolved in the heat-treated alloy matrix and the final grain size. It is evident from the graph that both after the boriding process and after the long-term annealing process, the analysed samples increased their resistance to wear. The surface of the samples in the T6 state after the boriding process, which lasted for 3600 minutes, can be described as the most resistant. The wear resistance of these samples was about $40 \%$ higher than the samples in the same condition without heat treatment. 
In addition to increasing the resistance of the surface to wear, the heat-treated alloy increased its resistance to the selected corrosion environment, see Fig. 8.

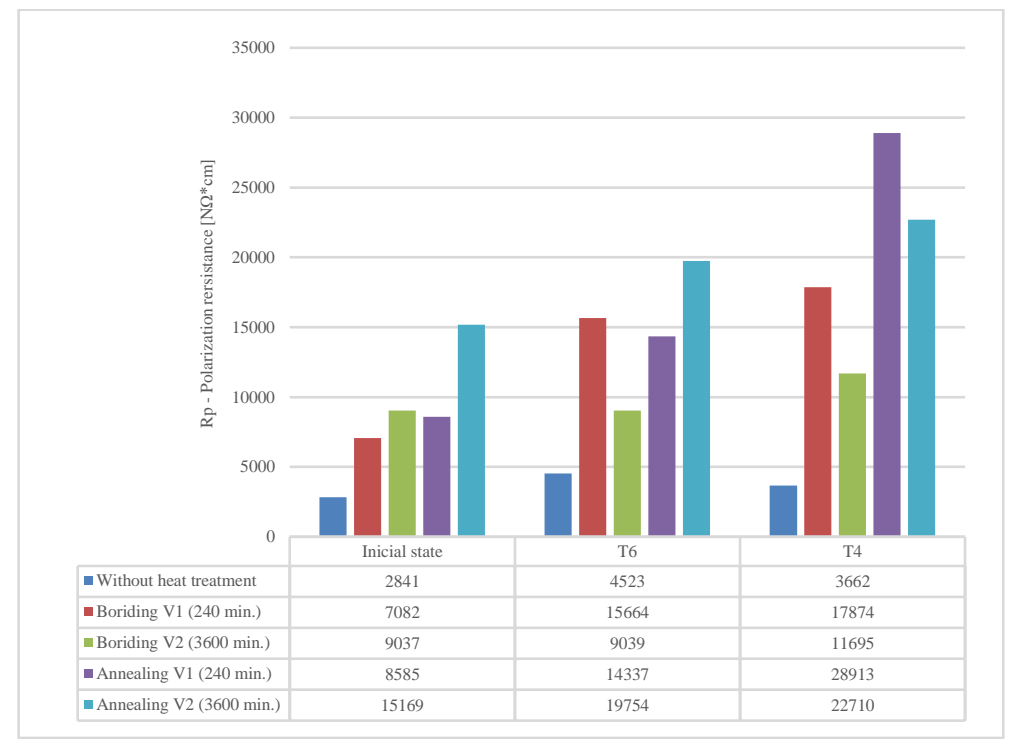

Fig. 8. Comparison of polarization resistance in the environment of $5 \mathrm{Wt}$. \% Aqueous $\mathrm{NaCl}$ solution

The highest corrosion resistance was shown by samples that were annealed for a long duration. In these samples, a passivation layer of $\mathrm{A} 12 \mathrm{O} 3$ was formed, which is very resistant to the selected corrosive environment. The samples after the boriding process also increased their resistance to the corrosion environment. Differences in corrosion resistance between samples that have undergone different aging and samples that have not been further processed are also associated with different degrees of dissolved elements in the alloy matrix due to their heat treatment.

\section{Conclusion}

The aim of this study was to assess the effect of boriding in the powder backfill on the microstructure and properties of the aluminium alloy EN AW 2024. The experimental results can be summarized as follows:

- As a result of heat treatment, the morphology of $\mathrm{Al}-\mathrm{Cu}-\mathrm{Mg}$ precipitates changed in the structure of the samples.

- No significant changes in morphology were observed for Al-Mn-Fe-Cu type precipitates, which are more temperature resistant.

- In the samples after the boriding process, a higher proportion of small $\mathrm{Al}-\mathrm{Cu}-\mathrm{Mg}$ precipitates was observed in the structure compared to the samples after long-term annealing.

- As a result of the heat treatment, the hardness of the aluminum matrix decreased, due to the dissolution of the precipitates in a solid solution, the matrix of this alloy.

- During the boriding process, a passive Al-Mg-F layer was formed on the surface of the samples. This layer reached a thickness of up to about $2 \mu \mathrm{m}$. In addition to this layer, the presence of an $\mathrm{Al}_{2} \mathrm{O}_{3}$ layer was noted on some sample surfaces.

- The Pin on Disk test showed that samples after the boriding process have a higher resistance to wear than samples without heat treatment and samples that have been annealed for a long time. The highest resistance to this type of wear was recorded for samples in the T6 state borided for 3600 minutes.

- There was no significant difference in the wear resistance of the T4 samples when comparing the borided samples and the long-term annealed samples for the same length of time.

- As a result of heat treatment, the corrosion resistance of EN AW 2024 aluminum alloy samples increased, both for the borided samples and for the samples after long-term annealing.

The above results show the relative contribution of the boriding process to some properties of the aluminum alloy EN AW 2024. However, to verify the results and the hypothesis, it would be necessary to perform further analyses, especially analysis using TEM and other techniques to confirm the ability of boron to affect the microstructure of these alloys using the boride powder backfilling process.

\section{Acknowledgments}

This article was made possible by the funding for the SGS-2018-051 project "Application of new treatment and test procedures to surfaces and bulk materials for improved usability of assemblies and work tools in industry". The article was created with the support of the Motivation System of the University of West Bohemia in Pilsen, part POSTDOC. 


\section{References}

[1] Liang, M.; Chen, L.; Zhao, G. \& Guo, Y. (2020). Effects of solution treatment on the microstructure and mechanical properties of naturally aged EN AW 2024 Al alloy sheet. Journal of Alloys and Compounds, 824, p.153943.

[2] Esmaeili, S.; Wang, X.; Lloyd, D. \& Poole, W. (2003). On the precipitation-hardening behavior of the Al-Mg-Si$\mathrm{Cu}$ alloy AA6111. Metallurgical and Materials Transactions A, 34(3), pp.751-763.

[3] Vlach, M.; Čížek, J.; Smola, B.; Melikhova, O.; Vlček, M.; Kodetová, V.; Kudrnová, H. \& Hruška, P. (2017). Heat treatment and age hardening of $\mathrm{Al}-\mathrm{Si}-\mathrm{Mg}-\mathrm{Mn}$ commercial alloy with addition of $\mathrm{Sc}$ and $\mathrm{Zr}$. Materials Characterization, 129, pp.1-8.

[4] Totten, G. \& MacKenzie, D. (2003). Handbook Of Aluminum. New York: Marcel Dekker.

[5] Fujda, M.; Mišičko, R.; Rusňáková, L. \& Sojko, M. (2007). Effect of Solution Annealing Temperature on Structure and Mechanical Properties of EN AW 2024 Aluminium Alloy. J. Met. Mater. Miner. 2007, 17, 35-40

[6] Goodarzy, M.; Arabi, H.; Boutorabi, M.; Seyedein, S. \& Hasani Najafabadi, S. (2014). The effects of room temperature ECAP and subsequent aging on mechanical properties of $2024 \mathrm{Al}$ alloy. Journal of Alloys and Compounds, 585, pp.753-759.

[7] Wang, P.; Li, H.; Prashanth, K.; Eckert, J. \& Scudino, S. (2017). Selective laser melting of Al-Zn-Mg-Cu: Heat treatment, microstructure and mechanical properties. Journal of Alloys and Compounds, 707, pp.287-290.

[8] Mohamed, A. \&Samuel, F. (2012). A Review on the Heat Treatment of Al-Si-Cu/Mg Casting Alloys. Heat Treatment - Conventional and Novel Applications,

[9] Hunsicker, H. (1980). Dimensional changes in heat treating aluminum alloys. Metallurgical Transactions A, 11(5), pp.759-773

[10] Su, R.; Xiao, J.; Jia, Y.; Wang, K. \& Qu, Y. (2019). Study on properties and microstructure of an Al-Cu-Mg-FeNi alloy with two-stage aging treatment. Materials Research Express, 6(12), p.126561.

[11] Carlson, O. (1990). The Al-B (Aluminum-Boron) system. Bulletin of Alloy Phase Diagrams, 11(6), pp.560-566.

[12] Duschanek, H. \& Rogl, P. (1994). The Al-B (aluminum-boron) system. Journal of Phase Equilibria, 15(5), pp.543552.

[13] Wang, X. (2005). The formation of AlB2 in an Al-B master alloy. Journal of Alloys and Compounds, 403(1-2), pp.283-287.

[14] Khaliq A.; Rhamdhani M.A.; Brooks G.A. \& Grandfield J. (2014). Analysis of Boron Treatment for V Removal Using AlB 2 and AlB 12 Based Master Alloys. In: Grandfield J. (eds) Light Metals 2014. Springer, Cham. https://doi.org/10.1007/978-3-319-48144-9_160

[15] Ağaoğulları, D.; Gökçe, H.; Duman, İ. \& Öveçoğlu, M. (2012). Aluminum diboride synthesis from elemental powders by mechanical alloying and annealing. Journal of the European Ceramic Society, 32(7), pp.1457-1462.

[16] Wang, X.; Brydson, R.; Jha, A. \& Ellis, J. (1999). Microstructural analysis of Al alloys dispersed with TiB2 particulate for MMC applications. Journal of Microscopy, 196(2), pp.137-145.

[17] Shandilya, P.; Jain, P. K. \& Misra, J. P. (2010). Experimental investigation during wire electric discharge cutting of SICP/6061 aluminium metal matrix composite. Proceedings of the 21st International DAAAM Symposium, Vol. 21, No. 1, ISSN 1726-9679

[18] Usurelu, E. M.; Butu, M.; Moldovan, P.; Semenescu, A. \& Gheorghe, D. (2010). Hybrid aluminum matrix composites obtained through processing in pasty status. Proceedings of the 21 st International DAAAM Symposium, Vol. 21, No. 1, ISSN 1726-9679

[19] ASTM G99-17. (2017). Standard Test Method for Wear Testing with a Pin-on-Disk Apparatus. ASTM International, West Conshohocken, PA. www.astm.org 